\title{
Fontes de informação para negócios: análise sobre frequência, relevância e confiabilidade, baseada em estudo empírico com empresários e gestores organizacionais
}

Frederico Cesar Mafra Pereira

Doutor e Mestre em Ciência da Informação (ECI/UFMG).Professor Permanente da Fundação Pedro Leopoldo (FPL/MG).

http://dx.doi.org/10.1590/1981-5344/2502

O presente trabalho relata um estudo sobre 0 comportamento informacional de empresários e gestores de micro, pequenas, médias e grandes empresas, com relação à escolha de fontes de informação para a solução de suas necessidades organizacionais. A metodologia se baseou em um estudo quantitativo, de caráter descritivo, com 67 entrevistas realizadas através de amostra não probabilística. Os resultados apontaram diferenças entre as escolhas e análise dos entrevistados sobre 34 fontes de informação para negócios definidas por Mafra Pereira e Barbosa (2009), não existindo uma correlação positiva entre as fontes mais acessadas e as fontes mais relevantes e confiáveis. As fontes de informação estritamente eletrônicas tendem a ser as mais acessadas, enquanto as fontes pessoais são consideradas as mais relevantes, sendo que as fontes internas às empresas nas quais os entrevistados trabalham são consideradas as mais confiáveis.

Palavras-chave: Fontes de informação; Fontes pessoais; Fontes impessoais; Fontes eletrônicas; Comportamento informacional. 


\title{
Business information sources: frequency, relevance and reliability analysis, based on empirical study with business and organizational managers
}

\begin{abstract}
This paper reports a study of the information behavior of entrepreneurs and managers of small, medium and large companies, concerning to the choice of information sources to solve their organizational needs. The methodology was based on a quantitative study of a descriptive nature, with 67 interviews conducted by nonprobabilistic sample. The results showed differences between the choices and analysis of respondents about the 34 business information sources defined by Mafra Pereira and Barbosa (2009), and there is not a positive correlation between the most accessed sources and the most relevant and reliable sources. In addition, the strictly electronic information sources tend to be the most accessible, while the personal sources are considered the most relevant, and the internal organizational sources are considered the most reliable.
\end{abstract}

Keywords: Information sources; Personal sources; Impersonal sources; Electronic sources; Information behavior.

Recebido em 10.08.2015 Aceito em 16.05.2016

\section{Introdução}

O atual contexto de intensa concorrência, globalização dos negócios e contínuo desenvolvimento tecnológico tem exigido, dos empresários e gestores organizacionais, a posse de informações precisas, relevantes e confiáveis. Levando-se em conta que todo empresário / gestor é um usuário da informação, compreender seu comportamento informacional é de fundamental importância para os provedores informacionais, o que envolve, dentre diversos aspectos, os critérios utilizados para a escolha das fontes de informação (frequência de uso, relevância e confiabilidade).

O presente trabalho focaliza o comportamento informacional de empresários e gestores de micro, pequenas, médias e grandes empresas, com relação à escolha das fontes de informação consideradas importantes para a solução de suas necessidades organizacionais. Como principal 
referencial teórico, foram utilizadas as 34 (trinta e quatro) fontes de informação para negócios, identificadas e avaliadas por Mafra Pereira e Barbosa (2009), e classificadas com relação aos critérios de relacionamento / proximidade (fontes pessoais ou impessoais / documentais) e de origem (fontes internas ou externas à empresa). Além disso, algumas fontes foram classificadas como estritamente eletrônicas (também subdivididas em fontes internas e externas à empresa).

O artigo foi estruturado em seis partes. Além desta introdução, a seção dois apresenta um referencial sobre fontes de informação, tipologias e categorizações. Na seção três, são apresentados os conceitos de comportamento de busca e de uso da informação, utilizados para explicar o comportamento informacional dos executivos e gestores participantes deste trabalho. Na seção quatro são detalhados os procedimentos metodológicos utilizados na pesquisa. Na $5^{a}$ seção, são apresentados e analisados os resultados obtidos quanto às fontes de informação mais acessadas, mais relevantes e mais confiáveis pelo público pesquisado. E por último, na seção seis, são feitas as considerações finais sobre o estudo.

\section{Fontes de Informação para negócios: tipologias e categorizações}

Muitos estudos, nacionais e internacionais, têm sido realizados em diversos segmentos empresariais, de características diferentes, e com profissionais e/ou empresas de todos os portes, tendo como foco as fontes de informação para negócios e aspectos relacionados à frequência de busca, relevância e confiabilidade destas fontes. Verifica-se que as fontes de informação são diversas, abrangem diferentes aspectos do ambiente das empresas, se constituem em importante recurso para os negócios (BARBOSA, 2002), e a variedade de classificações atendem a segmentos ou setores de negócios específicos.

Um dos primeiros estudos sobre fontes de informação é de Aguilar (1967), o qual afirmava que as informações necessárias às organizações para o monitoramento do seu ambiente de negócios eram sempre informações externas, e quase sempre advindas de fontes externas. Também distinguia as fontes de informação como pessoais e impessoais, sendo as fontes pessoais aquelas que envolviam interação entre pessoas durante o processo de busca, e as fontes impessoais aquelas em que 0 pesquisador se utilizava de canais de comunicação que não implicam na interação face-a-face com o provedor da informação. Através destas quatro formas de categorização de fontes de informação, Aguilar as organizou como fontes externas pessoais, fontes externas impessoais, fontes internas pessoais e fontes internas impessoais.

Num outro estudo com, aproximadamente, 500 empresas multinacionais de grande porte nos Estados Unidos sobre o acesso à informação, Kobrin et al. (1980) classificaram as fontes de informação em duas categorias: internas e externas. Para Degent (1986), as fontes de 
informação utilizadas pela maioria das empresas podiam ser classificadas através dos seguintes tipos: competidores, governo, fornecedores, clientes, associações profissionais, associações de classe, empregados, consultores e imprensa especializada. Já Montalli (1987) classificou as fontes de informação em três tipos: fontes de informações técnicas, fontes de informação para negócios e fontes de informação científicas.

Sutton (1988) identificou quatro grupos de fontes de informação destacadas como importantes pelos administradores: fontes internas, contatos diretos com o setor de negócios, informações publicadas e outras fontes. Os autores Smeltzer, Fann e Nikolaisen (1988) analisaram a prática de monitoramento ambiental por gerentes de pequenas empresas localizadas nos estados de Phoenix e Kansas, nos Estados Unidos, e também classificaram as fontes de informação como fontes pessoais e fontes impessoais, sendo as primeiras (principalmente, familiares e clientes) consideradas muito mais importantes do que as fontes impessoais, na visão dos entrevistados em seu trabalho.

Em estudo realizado junto a gerentes de planejamento de sete grandes empresas do Reino Unido, Lester e Waters (1989) apontaram seis tipos de fontes de informação utilizados no trabalho de monitoramento ambiental: as fontes formais (ou publicáveis) e as fontes informais, as fontes internas e as fontes externas, e as fontes pessoais e as fontes impessoais.

Fuld (1993) apontou algumas fontes de informação utilizadas no trabalho de monitoração da concorrência, sem, entretanto, tê-las categorizado: artigos de jornais, revistas, publicações especializadas, relatórios de analistas de investimentos, estudos publicados, planos de expansão, anúncios dirigidos, anúncios de ofertas de emprego, calendários de eventos, exposições e feiras, pesquisas especiais, clippings de notícias, literatura sobre produtos, arquivos públicos e contatos pessoais.

Outro autor que apresentou uma ampla revisão bibliográfica de diversos trabalhos de outros autores que estudaram o tema 'fontes de informação', e como estes as classificaram, foi Choo (1994). Segundo ele, as fontes de informação podiam ser classificadas, de maneira geral, em quatro categorias: fontes internas ou externas (em relação à organização), e fontes pessoais ou impessoais. Esta tipologia de classificação foi também utilizada em seu estudo, tendo sido reorganizada, gerando quatro novas categorias: fontes pessoais internas, fontes pessoais externas, fontes impessoais internas e fontes impessoais externas.

Em outro estudo, Choo (1998) apresentou uma categorização de fontes de informação em três níveis: fontes pessoais (subdivididas em fontes internas ou externas); fontes documentais (subdivididas em fontes publicáveis ou documentos internos da organização) e fontes eletrônicas (formadas pelas bases de dados online, CD-ROMs e Internet). Com relação a estas últimas, em especial, Choo (1998) destacou a importância da Internet no processo de disseminação da informação, e citou o e-mail, 
os grupos e chats de discussão, os grupos de notícias, os sites e os portais como fontes eletrônicas que se utilizam da Internet como meio de transmissão de informações ("Internet como um espaço social informacional"). Além disso, a própria Internet foi também considerada como fonte de informação.

Carmo e Pontes (1999) apresentaram uma classificação de fontes de informação, afirmando que o trabalho de coleta, organização, processamento e análise da informação realizado pelas empresas devia ser norteado pela estratégia de negócios e pelos fatores críticos de sucesso de cada uma. Desta forma, cada empresa deveria buscar informações tanto em fontes formais quanto informais, e em fontes internas ou externas, no sentido de possibilitar agregar valor à informação coletada.

Estudo de Barbosa (2002) sobre monitoração ambiental organizacional externa, realizado junto a 91 profissionais de empresas privadas nacionais, multinacionais e organizações do setor público no Brasil, apresentou as fontes de informação organizadas em cinco categorias: fontes pessoais internas, fontes pessoais externas, fontes documentais internas, fontes documentais externas e outras fontes externas.

Cendón (2002) definiu o conjunto de informações usadas por administradores para a tomada de decisão como "informação para negócios", considerada um subconjunto da informação tecnológica, a qual foi definida como todo tipo de informação que contribui para o desenvolvimento industrial, englobando conhecimento técnico, econômico, mercadológico, gerencial e social. As informações para negócios incluíam: informações mercadológicas, financeiras, estatísticas, jurídicas e informações sobre empresas e produtos, além de outras sobre tendências nos cenários político-social, econômico e financeiro nos quais operam as organizações (SOUZA; BORGES, 1996; SOUZA, 1996; MONTALLI, 1994). Neste ponto, Cendón (2002) descreveu algumas das principais bases de dados estrangeiras de informação para negócios, agrupando-as em 10 categorias: (1) notícias em geral, (2) informações sobre empresas e setores industriais, (3) diretórios de empresas, (4) informações sobre produtos, (5) informações biográficas, (6) informações financeiras, (7) informações para investimento, (8) pesquisas de mercado, informações jurídicas e (10) informações estatísticas.

Cendón (2002) também alertou para a tendência de evolução das redes de comunicação, através das quais a informação, em formato eletrônico, ganha em importância e volume. $E$ dentre os recursos informacionais em formato eletrônico, destacou as páginas da Internet e as bases de dados. Especificamente com relação à Internet, a autora afirmou que, apesar dela não substituir a informação contida nas bases de dados, seu advento como fonte alternativa de informação eletrônica em rede impactou a forma como as empresas passaram a oferecer e buscar informações online, procurando as melhores formas de se inserirem no novo contexto, e a utilizando com um meio alternativo de acesso às bases 
de dados, produtos e serviços. Ao mesmo tempo, a Internet propicia ampliação do leque de serviços e oferece uma variedade maior de produtos que se baseiam em acesso via Web, sendo estes mais interativos. Neste sentido, Pereira (2003) destacou que a Internet já poderia ser considerada a maior fonte de informação da história, devido aos inúmeros portais de conhecimento e de oportunidades criadas, através de homepages e sites que "colocam o ser humano no centro do futuro".

Em outro estudo feito por Cendón (2003) analisando as bases de dados para negócios existentes especificamente no Brasil, a autora afirmou que o termo 'informação para negócios' só apareceu na literatura brasileira por volta de 1994 (MONTALLI, 1994; FIGUEIREDO, 1994). Neste trabalho, Cendón (2003) categorizou nove tipos de bases de dados de informação para negócios no Brasil: (1) informações bibliográficas; (2) informações sobre empresas e produtos; (3) informações financeiras; (4) informações estatísticas e indicadores econômicos; (5) informações sobre oportunidades de negócios; (6) informações biográficas; (7) informações para investimentos; (8) bases de dados jurídicas e; (9) informações do tipo "vocabulário". Estes nove tipos de bases de dados são disponibilizados através de CD-ROM, Internet, disquete, cópia demonstrativa, consultoria, tele-atendimento, de forma online, por e-mail, Intranet, sob a forma impressa, ou disponibilizada no local do produtor da informação.

Em seu trabalho de dissertação, Pereira (2003) também apresentou uma classificação de fontes de informação utilizadas pelas empresas, baseada em três principais fluxos informacionais existentes nas organizações (LESCA; ALMEIDA, 1994): a) fluxo de informações criadas pela empresa para seu próprio uso; b) fluxo de informações produzidas pela empresa com orientação para fora dela e; c) fluxo de informações coletadas externamente e orientadas para dentro da empresa.

De acordo com a autora, observando-se os três fluxos de informação citados, poder-se-ia identificar quatro grupos de informação existentes nas organizações: as informações internas, as externas, as formais e as informais. Afirmou ainda que, na prática, são encontradas nas empresas combinações dessas quatro classificações: as informações internas e formais correspondem à quase totalidade das informações tratadas pelos sistemas de informações, sejam operacionais ou de apoio à decisão; as informações internas e informais aparecem nas organizações que utilizam correio eletrônico; as informações externas e formais estão presentes nas organizações que praticam benchmarking ${ }^{2}$ ou que possuem

\footnotetext{
${ }^{1}$ Para Cendón, em e-mail respondido a este autor, as bases do tipo "vocabulário" se dividem em dois subtipos, que são dicionários e tesauros. Ou seja, tanto as bases de dicionários como os tesauros são consideradas bases do tipo "vocabulário".

2 "Benchmarking é uma ferramenta de gestão que consiste na mensuração da performance de uma organização, permitindo que ela compare sua eficiência com a de outras organizações, frequentemente com a empresa líder do segmento ou outro concorrente muito relevante. Esta prática não significa copiar o que a concorrência está fazendo, mas aprender com ela através da observação e comparação das melhores práticas". Disponível em
} 
módulos de informações sobre clientes, concorrentes e mercados em seus sistemas de informações de marketing; e as informações externas e informais não são registradas de forma sistêmica (POZZEBON; FREITAS; PETRINI, 1997).

Os trabalhos de Mafra Pereira (2006) e de Mafra Pereira e Barbosa (2008) identificaram mais de uma centena de fontes de informação citadas pela literatura e utilizadas pelas empresas em atividades de inteligência empresarial, aprendizagem organizacional ou para tomada de decisão. Estas fontes foram apresentadas a alguns consultores empresariais, atuantes no mercado de Belo Horizonte (MG), com a intenção de que eles identificassem as fontes mais utilizadas e/ou que poderiam ser utilizadas em atividades de consultoria. Ao final, foram identificadas 30 fontes de informação, que foram classificadas segundo os critérios de origem (fontes internas ou externas), relacionamento / proximidade (fontes pessoais ou impessoais) e mídia (fontes eletrônicas e não-eletrônicas.

Utilizando-se das mesmas referências e da base de fontes de informação dos seus trabalhos anteriores, Mafra Pereira e Barbosa (2009) identificaram 34 (trinta e quatro) fontes de informação utilizadas por gestores empresariais para a coleta de informações voltadas a processos decisórios, categorizadas, em primeiro lugar, pelo critério de relacionamento / proximidade (fontes pessoais ou impessoais / documentais). Num segundo plano, as fontes foram classificadas por origem (fontes internas ou externas), ou seja, em relação à empresa na qual trabalham os gestores. Todas as fontes categorizadas segundo os dois primeiros critérios foram consideradas como fontes não-eletrônicas, já que, em tese, as informações disponibilizadas pelas mesmas poderiam existir por outros meios que não apenas o eletrônico. Por isso, foi constituída uma categoria em especial para agregar as fontes consideradas estritamente eletrônicas, sendo estas também subdividas entre fontes internas e externas.

Portanto, dentre os autores abordados como referencial teórico sobre fontes de informação, são apresentados na Tabela aqueles cujas categorizações serviram de base para a proposta de classificação das fontes de informação a serem utilizadas neste trabalho.

Tabela 1 - Autores e as principais categorias de fontes de informação ${ }^{3}$

\begin{tabular}{l|l}
\hline \multicolumn{1}{c|}{ Autores } & \multicolumn{1}{c}{ Categorização das fontes de informação } \\
\hline \hline Aguilar (1967) & Fontes externas - Fontes internas \\
& Fontes pessoais - Fontes impessoais \\
\hline Kobrin et al. (1980) & Fontes internas - Fontes externas \\
\hline Sutton (1988) & Fontes internas \\
\hline
\end{tabular}

http://www.administradores.com.br/artigos/negocios/o-que-e-benchmarking/48104/. Acesso em 25/07/2015.

${ }^{3}$ Nem todos os autores citados no referencial teórico sobre fontes de informação estão representados na Tabela 1 , ou por não apresentarem uma categorização mínima para as fontes citadas, ou por apresentarem uma categorização de fontes de informação diferente ou muito particular aos seus trabalhos. Estes não foram considerados na configuração da categorização das fontes de informação utilizadas. Contudo, as fontes de informação citadas por estes autores serviram de referência para a pesquisa realizada e a definição da lista de fontes de informação para negócios (apresentada na Tabela 2). 


\begin{tabular}{l|l}
\hline & $\begin{array}{l}\text { Contatos diretos com o setor de negócios } \\
\text { Informações publicadas } \\
\text { Outras fontes }\end{array}$ \\
\hline Smeltzer, Fann e Nikolaisen (1988) & Fontes pessoais - Fontes impessoais \\
\hline Lester e Waters (1989) & $\begin{array}{l}\text { Fontes formais (ou publicáveis) - Fontes informais } \\
\text { Fontes internas - Fontes externas } \\
\text { Fontes pessoais - Fontes impessoais }\end{array}$ \\
\hline Choo (1994) & $\begin{array}{l}\text { Fontes pessoais internas - Fontes pessoais externas } \\
\text { Fontes impessoais internas - Fontes impessoais } \\
\text { externas }\end{array}$ \\
\hline Choo (1998) & $\begin{array}{l}\text { Fontes pessoais internas - Fontes pessoais externas } \\
\text { Fontes documentais publicáveis }\end{array}$ \\
& $\begin{array}{l}\text { Fontes documentais (doc. Internos da organização) } \\
\text { Fontes eletrônicas }\end{array}$ \\
\hline Carmos e Pontes (1999) & $\begin{array}{l}\text { Fontes formais - Fontes informais } \\
\text { Fontes internas - Fontes externas }\end{array}$ \\
\hline Pereira (2003) & $\begin{array}{l}\text { Fontes pessoais internas - Fontes pessoais externas } \\
\text { Fontes documentais internas - Fontes documentais } \\
\text { externas } \\
\text { Outras fontes externas }\end{array}$ \\
\hline Mafra Pereira (2006) Mafra Pereira e & $\begin{array}{l}\text { Fontes internas - Fontes externas } \\
\text { Fontes formais - Fontes informais }\end{array}$ \\
\hline Fontes internas - Fontes externas \\
& Fontes pessoais - Fontes impessoais \\
Fontes eletrônicas - Fontes não eletrônicas
\end{tabular}

Fonte: Elaborado pelo autor.

Para este trabalho, foram utilizadas como referência principal as 34 (trinta e quatro) fontes de informação, identificadas e avaliadas por Mafra Pereira e Barbosa (2009) (Tabela 2).

Tabela 2 - Fontes de Informação para Negócios

\section{FONTES PESSOAIS}

\section{INTERNAS}

1. Empresários / Executivos (nível estratégico)

2. Diretores / Gerentes (nível tático)

3. Demais empregados (nível operacional)

\section{EXTERNAS}

4. Amigos / conhecidos / familiares

5. Clientes

6. Concorrentes

7. Parceiros / Fornecedores / Distribuidores

8. Funcionários de órgãos públicos / governo

9. Empresários / Executivos de outras empresas

10. Consultores / Analistas / Profissionais

Liberais / Advogados / Publicitários /

Universidades

11. Ex-funcionários de empresas diversas / concorrentes

12. Associações comerciais / empresariais / de classe

13. Bancos / Agentes financeiros / Bolsa de 
Valores

\section{FONTES IMPESSOAIS / DOCUMENTAIS}

\section{INTERNAS}

14.Atas de reuniões

15.Relatórios, projetos e pesquisas dos setores da empresa

16. Memorandos / circulares / minutas /

políticas e normas

17.Clippings / Press releases

18. Biblioteca / Centro de Doc. e Informação interno

\section{EXTERNAS}

19. Bibliotecas públicas / de empresas

20. Jornais e Revistas

21. Periódicos de negócios / artigos / teses / monografias

22. Relatórios de negócios / financeiros / de mercado (pesquisa)

23. Publicações governamentais

24. Leis e regulamentações / patentes / normas técnicas

25. Material promocional de empresas /

concorrentes

26. Congressos, feiras, eventos (anais)

\section{FONTES ESTRITAMENTE ELETRÔNICAS}

\section{INTERNAS}

27. Newsletter da empresa

28. Intranet / Portal corporativo

29.Bases de dados da empresa

\section{EXTERNAS}

30. Sites / Portais de empresas, Universidades, Governo

31. Sites de busca na WEB (Google, Yahoo, Wikipédia)

32. Newswires (publicações abertas online)

33. Newsletters de empresas / concorrentes

34. Rádio e TV

Fonte: Elaborado pelo autor, com base em MAFRA PEREIRA; BARBOSA (2009).

\section{Comportamento de busca e uso da informação}

Wilson (2000) apresenta quatro definições relacionadas ao comportamento do usuário quando de sua busca por informação e, consequentemente, seu uso posterior (ou sua finalidade). São conceitos que se relacionam e se sobrepõem, sendo suas semelhanças relacionadas ao "comportamento informacional do usuário de informação", e suas diferenças referem-se ao grau de "refinamento" na busca por informações e no consequente uso das mesmas.

O primeiro conceito é o de 'comportamento informacional' (Information Behavior). Este é um conceito mais amplo, e refere-se ao comportamento do usuário de informação frente às diversas fontes e canais de informação, podendo ser um comportamento de busca 'ativo' ou 'passivo', além do seu comportamento no uso da informação adquirida. Um comportamento 'ativo' é aquele onde o demandante da informação procura, intencionalmente, por uma informação, como, por exemplo, numa comunicação face-a-face com outra pessoa, ou numa busca pela Internet. Já o comportamento 'passivo' refere-se àquele onde o demandante da informação não procura, intencionalmente, pela informação, mas esta é apresentada a ele (através de um programa de TV ou noticiário no rádio, por exemplo).

O segundo conceito é o de 'comportamento de busca informacional' (Information Seeking Behavior), e refere-se à busca ('ativa') de 
informação, por parte do demandante, para satisfazer a uma necessidade ou objetivo. Neste caso, o demandante da informação pode se utilizar de sistemas manuais (como jornais, revistas, bibliotecas) ou de sistemas computacionais (como a Internet).

O terceiro conceito é o de 'comportamento de pesquisa informacional' (Information Searching Behavior), e refere-se a uma busca de informação mais focalizada, em que o demandante da informação interage com sistemas computacionais ou com sistemas de busca que determinam critérios para a seleção da informação demandada. Em ambos os casos, o demandante define se a informação adquirida é relevante ou não para ele. Segundo Barbosa (2002), "uma informação é considerada relevante quando é necessária e útil para o alcance dos objetivos e metas da organização".

Portanto, o comportamento de busca por informação pode ser explicado pelos conceitos de Information Seeking Behavior e Information Searching Behavior, os quais são, de certa forma, relacionados e sobrepostos. A diferença entre os dois conceitos é que, no primeiro, a busca pode ser considerada mais ampla, tendo o demandante definido sua necessidade ou objetivo, mas cuja busca pode trazer ou não informações relevantes para ele. No segundo, o comportamento de busca torna-se mais rigoroso, e com um nível de refinamento maior, já que o demandante da informação avalia se a informação buscada é relevante ou não para sua necessidade. Também em Aguilar (1967) e Auster e Choo (1994), os termos seeking e searching são abordados quando do estudo da atividade de monitoração ambiental (scanning). Segundo estes autores, a atividade de scanning envolve vários modos de busca de informação, sendo que a pesquisa informacional (searching) trata de uma busca mais específica. Por outro lado, o demandante da informação pode ter um comportamento de busca que não seja tão refinado ou específico (seeking) (AUSTER; CHOO, 1994). Portanto, o conceito de comportamento de busca por informação utilizado neste trabalho está baseado nestes dois conceitos, de forma conjunta, não tendo sido feita nenhuma diferenciação entre ambos no momento da realização desta pesquisa.

Finalizando, o quarto e último conceito apresentado por Wilson (2000) é o de 'comportamento de uso da informação' (Information Use Behavior). Este é considerado o passo seguinte aos conceitos de comportamento de busca e de pesquisa da informação, já que o demandante da informação busca a informação (seeking) e, considerando-a relevante (searching), incorpora-a a sua base de conhecimento.

\section{Procedimentos metodológicos}

A metodologia de pesquisa deste trabalho se dividiu em duas etapas distintas e subsequentes. Na primeira, foi realizada pesquisa bibliográfica (MATTAR, 1996; SAMARA; BARROS, 2002) para mapeamento e 
identificação das fontes de informação e categorias a serem utilizadas na pesquisa, tendo sido escolhida a proposta desenvolvida por Mafra Pereira e Barbosa (2009), já devidamente explicitada no referencial teórico.

Com base nesta primeira definição, foi elaborado um instrumento de coleta do tipo questionário estruturado quantitativo, o qual foi submetido a um pré-teste com empresários e gestores selecionados através de amostra não-probabilística por julgamento (ou intencional) (MAFRA PEREIRA, 2000; MALHOTRA, 2001; SAMARA; BARROS, 2002), sendo este procedimento realizado no mês de agosto de 2014.

Após a realização do pré-teste e posteriores ajustes ao instrumento de coleta, foi realizada pesquisa descritiva quantitativa (MAFRA PEREIRA, 2000), com o objetivo de levantar informações sobre o perfil dos empresários e executivos entrevistados (pertencentes a empresas de micro, pequeno, médio e grande portes, localizadas em Minas Gerais, e pertencentes aos segmentos da indústria, comércio e serviços) e respectivas empresas nas quais atuam como decisores, além de aspectos relacionados ao comportamento de busca e de uso sobre as fontes de informação utilizadas pelos entrevistados.

Foram aplicados 67 (sessenta e sete) questionários estruturados não-disfarçados, junto a empresários e gestores de empresas mineiras, pertencentes a cursos de Mestrado em Administração e de Pós-Graduação em Gestão Estratégica de duas instituições de ensino atuantes no mercado de Minas Gerais, nos quais o pesquisador atua como professor. As entrevistas foram realizadas entre os meses de outubro de 2014 e abril de 2015. A amostra, neste caso, também é caracterizada como sendo do tipo não-probabilística por julgamento (intencional).

\section{Apresentação e análise dos resultados}

\subsection{Perfil dos entrevistados e das empresas nas quais atuam}

Dentre os 67 empresários e executivos entrevistados, $64,2 \%$ são do sexo masculino e $35,8 \%$ do sexo feminino. A maioria possui idade entre 25 e 34 anos (47,8\% da amostra), seguidos dos de até 25 anos $(16,4 \%)$, de 35 a 44 anos $(14,9 \%)$ e dos de 45 a 54 anos (13,4\%). $44,8 \%$ dos entrevistados atuam como Gerentes / Coordenadores, responsáveis pela tomada de decisões no nível tático de suas empresas (setores e/ou departamentos), 10,5\% são alocados como Executivos / CEO / Diretores, responsáveis pela tomada de decisões no nível estratégico de suas empresas, e 10,4\% são Empresários / Sócios em suas organizações, também responsáveis pela tomada de decisões em nível estratégico. Os demais respondentes estão alocados em nível funcional / operacional, mas também responsáveis pela tomada de decisões em suas atividades.

A maioria dos entrevistados $(58,2 \%)$ está alocada em grandes empresas (com 100 funcionários ou mais), 10,4\% em médias empresas (com 50 a 99 funcionários), 13,5\% em pequenas empresas (com 10 a 49 
funcionários), e 17,9\% em micro empresas (com até 9 funcionários) ${ }^{4}$. As empresas identificadas neste trabalho representam todos os setores da economia brasileira - agronegócios, indústria, comércio e serviços.

\subsection{Comportamento de busca por informação pelos entrevistados}

Com relação ao comportamento de busca dos executivos e gestores entrevistados por fontes de informação, foram analisados os aspectos de frequência de busca, grau de relevância da fonte e grau de confiabilidade, referentes às 34 fontes de informação escolhidas.

Tabela 3 - Frequência de busca por fonte de informação

\begin{tabular}{|c|c|c|c|c|c|c|c|c|}
\hline Fontes de Informação & 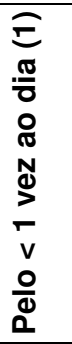 & 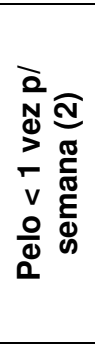 & 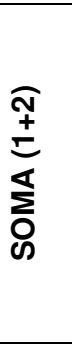 & 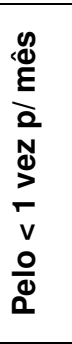 & 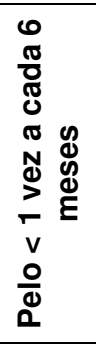 & 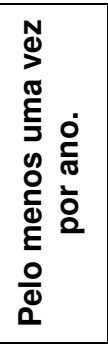 & 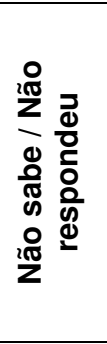 & 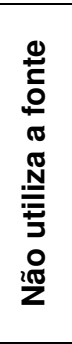 \\
\hline Sites de busca na WEB (Google, Yahoo, Wikipédia) & 79,1 & 16,4 & 95,5 & 3,0 & 1,5 & -- & -- & -- \\
\hline Demais empregados (nível operacional) & 61,2 & 23,9 & 85,1 & 6,0 & 6,0 & -- & -- & 3,0 \\
\hline Jornais e Revistas & 52,2 & 29,9 & 82,1 & 7,5 & 4,5 & 1,5 & 1,5 & 3,0 \\
\hline Rádio e TV & 70,1 & 10,4 & 80,5 & 7,5 & 3,0 & -- & 3,0 & 6,0 \\
\hline Amigos / conhecidos / familiares & 37,3 & 38,8 & 76,1 & 19,4 & 3,0 & -- & -- & 1,5 \\
\hline Clientes & 41,8 & 31,3 & 73,1 & 19,4 & 1,5 & -- & -- & 6,0 \\
\hline Bases de dados & 49,3 & 22,4 & 71,7 & 7,5 & 4,5 & 1,5 & 3,0 & 11,9 \\
\hline $\begin{array}{l}\text { Sites / Portais de empresas, Universidades, } \\
\text { Governo }\end{array}$ & 38,8 & 31,3 & 70,1 & 16,4 & 4,5 & 3,0 & 3,0 & 3,0 \\
\hline Intranet / Portal Corporativo & 44,8 & 20,9 & 65,7 & 9,0 & 3,0 & -- & 6,0 & 16,4 \\
\hline Diretores / Geren & 28,4 & 37,3 & 65,7 & 26,9 & 1,5 & 1,5 & -- & 4,5 \\
\hline Empresários / Executivos (nível estratégico) & 22,4 & 32,8 & 55,2 & 17,9 & 9,0 & 7,5 & -- & 10,4 \\
\hline Parceiros / Fornece & 14,9 & 40,3 & 55,2 & 32,8 & 9,0 & -- & -- & 3,0 \\
\hline Newswires (public & 25,4 & 26,9 & 52,3 & 13,4 & 3,0 & 3,0 & 3,0 & 25,4 \\
\hline Clippings / Press releases & 17,9 & 34,3 & 52,2 & 16,4 & 7,5 & 3,0 & 3,0 & 17,9 \\
\hline Newsletter da empresa & 14,9 & 28,4 & 43,3 & 26,9 & 3,0 & 1,5 & 7,5 & 17,9 \\
\hline $\begin{array}{l}\text { Memorandos / circulares / minutas / políticas e } \\
\text { normas }\end{array}$ & 13,4 & 25,4 & 38,8 & 19,4 & 19,4 & 6,0 & 7,5 & 9,0 \\
\hline $\begin{array}{l}\text { Consultores / Analistas / Profissionais Liberais/ } \\
\text { Advogados / Publicitários / Universidades }\end{array}$ & 13,4 & 25,4 & 38,8 & 22,4 & 20,9 & 10,4 & 1,5 & 6,0 \\
\hline Material promocional de empresas / concorrentes & 14,9 & 22,4 & 37,3 & 32,8 & 10,4 & 7,5 & -- & 11,9 \\
\hline $\begin{array}{l}\text { Relatórios, projetos e pesquisas dos setores da } \\
\text { empresa }\end{array}$ & 13,4 & 23,9 & 37,3 & 25,4 & 11,9 & 13,4 & 1,5 & 10,4 \\
\hline $\begin{array}{l}\text { Relatórios de negócios / financeiros / de mercado } \\
\text { (pesquisa) }\end{array}$ & 17,9 & 17,9 & 35,8 & 20,9 & 14,9 & 6,0 & 3,0 & 19,4 \\
\hline Newsletters de empresas / concorrentes & 16,4 & 17,9 & 34,3 & 28,4 & 7,5 & 1,5 & 4,5 & 23,9 \\
\hline $\begin{array}{l}\text { Periódicos de negócios / artigos / teses / } \\
\text { monografias }\end{array}$ & 16,4 & 16,4 & 32,8 & 32,8 & 4,5 & 4,5 & 6,0 & 19,4 \\
\hline Concorrentes & 11,9 & 19,4 & 31,3 & 26,9 & 23,9 & 7,5 & 1,5 & 9,0 \\
\hline $\begin{array}{l}\text { Biblioteca / Centro de Documentação e Informação } \\
\text { interno }\end{array}$ & 6,0 & 20,9 & 26,9 & 25,4 & 11,9 & 11,9 & 7,5 & 16,4 \\
\hline $\begin{array}{l}\text { Leis e regulamentações / Patentes / Normas } \\
\text { Técnicas }\end{array}$ & 6,0 & 19,4 & 25,4 & 22,4 & 13,4 & 11,9 & 7,5 & 19,4 \\
\hline Funcionários de órgãos públicos / Governo & 4,5 & 20,9 & 2 & 22,4 & 16,4 & 13,4 & 3,0 & 19,4 \\
\hline Publicações & 10,4 & 14,9 & 25,3 & 22,4 & 10,4 & 9,0 & 6,0 & 26,9 \\
\hline Bancos / Agentes financeiros / Bolsa de Valores & 10,4 & 14,9 & 25,3 & 19,4 & 11,9 & 13,4 & 10,4 & 19,4 \\
\hline Atas de reuniões & 3,0 & 20,9 & 23,9 & 26,9 & 13,4 & 7,5 & 6,0 & 22,4 \\
\hline ações come & 1,5 & 20,9 & 22,4 & 20,9 & 22,4 & 10,4 & 6,0 & 17,9 \\
\hline Empresários / Executivos de outras empresas & 3,0 & 17,9 & 20,9 & 28,4 & 20,9 & 4,5 & 7,5 & 17,9 \\
\hline Ex-Funcionários de empresas diversas / & 1,5 & 13,4 & 14,9 & 22,4 & 23,9 & 14,9 & 9,0 & 14,9 \\
\hline
\end{tabular}

\footnotetext{
${ }^{4}$ Conforme critério de classificação adotado pelo Serviço de Apoio às Micro e Pequenas Empresas - SEBRAE (2015).
} 
concorrentes

Congressos, feiras, eventos (anais)

Bibliotecas públicas / de empresas

Fonte: Elaborado pelo autor.

Com relação à frequência de busca por fontes de informação, foram apresentadas aos entrevistados as 34 (trinta e quatro) fontes definidas por Mafra Pereira e Barbosa (2009), e solicitado a cada um que optasse por um dos 6 (seis) pontos da escala de frequência de busca, sendo: 1) Não utilizo esta fonte de informação; 2) Sim, utilizo pelo menos uma vez por dia; 3) Sim, utilizo pelo menos uma vez por semana; 4) Sim, utilizo pelo menos uma vez por mês; 5) Sim, utilizo pelo menos uma vez a cada 6 meses; 6) Sim, utilizo pelo menos uma vez por ano.

Os resultados apontaram que, dentre as 10 fontes mais acessadas pelos entrevistados (soma das opções 'Pelo menos uma vez ao dia' e 'Pelo menos uma vez por semana'), cinco são fontes estritamente eletrônicas, e quatro são fontes pessoais. Além disso, houve um equilíbrio entre fontes internas (quatro) e fontes externas (seis), dentre as 10 mais acessadas. Mais especificamente quanto às fontes estritamente eletrônicas, a de maior frequência de busca foi 'Sites de busca na WEB (Google, Yahoo, Wikipédia)', que é uma fonte externa. Já a $2^{a}$ fonte mais acessada é uma fonte interna pessoal - 'Demais empregados (nível operacional)'.

De forma geral, pode-se inferir que as fontes eletrônicas têm destaque como as mais buscadas pelos usuários pela facilidade e rapidez com que estes conseguem pesquisar e acessar as informações através dessas fontes (Information Seeking Behavior), na maioria em grande volume, o que permite maior tempo para o trabalho de filtragem e escolha das melhores informações para suas necessidades. Há um equilíbrio entre fontes eletrônicas internas e externas, com destaque para os sites de busca de informação, como já citado.

As fontes pessoais são também priorizadas para a busca de informações para negócios, da mesma forma, pela facilidade e rapidez de acesso por parte dos usuários, já que são fontes pertencentes à rede de contatos dos entrevistados, tanto interna quanto externa à empresa. Confirmando tal análise, tem-se que, internamente, colegas de trabalho pertencentes ao nível operacional / funcional (ou de execução de ações) e ao nível tático (gerentes e diretores) são as fontes mais acessadas pelos entrevistados. Externamente, os amigos/conhecidos/familiares e os clientes se destacam como fontes pessoais mais acessadas pelos empresários e gestores entrevistados.

Tabela 4 - Grau de relevância da fonte de informação

\begin{tabular}{|c|c|c|c|c|c|c|c|c|}
\hline Fontes de Informação & 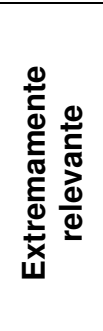 & 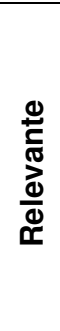 & 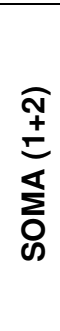 & 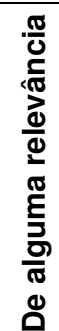 & 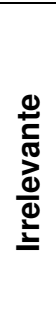 & 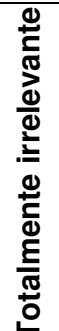 & 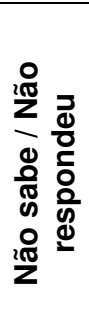 & 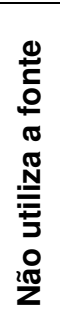 \\
\hline
\end{tabular}

Perspectivas em Ciência da Informação, v.21, n.2, p.100-119, abr./jun. 2016 


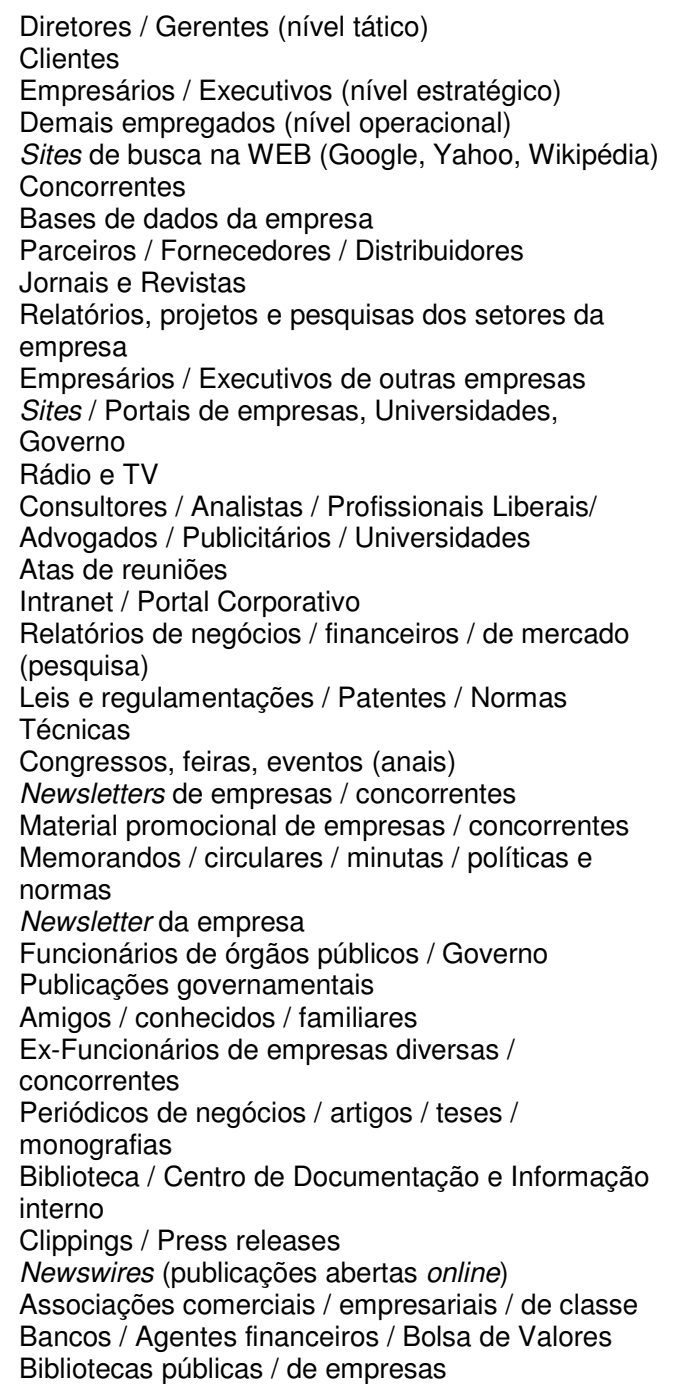

\begin{tabular}{|c|c|c|c|c|c|c|c|}
\hline 43,3 & 40,3 & 83,6 & 6,0 & 3,0 & 3,0 & -- & 4,5 \\
\hline 55,2 & 26,9 & 82,1 & 4,5 & 3,0 & 4,5 & -- & 6,0 \\
\hline 43,3 & 29,9 & 73,2 & 7,5 & 4,5 & 4,5 & -- & 10,4 \\
\hline 28,4 & 43,3 & 71,7 & 23,9 & 1,5 & -- & -- & 3,0 \\
\hline 29,9 & 40,3 & 70,2 & 26,9 & -- & 3,0 & -- & -- \\
\hline 34,3 & 35,8 & 70,1 & 17,9 & 3,0 & -- & -- & 9,0 \\
\hline 32,8 & 37,3 & 70,1 & 11,9 & 3,0 & 3,0 & -- & 11,9 \\
\hline 22,4 & 46,3 & 68,7 & 25,4 & 1,5 & 1,5 & -- & 3,0 \\
\hline 19,4 & 46,3 & 65,7 & 25,4 & 4,5 & 1,5 & -- & 3,0 \\
\hline 22,4 & 41,8 & 64,2 & 19,4 & 4,5 & 1,5 & -- & 10,4 \\
\hline 11,9 & 43,3 & 55,2 & 23,9 & 3,0 & 1,5 & -- & 16,4 \\
\hline 6,0 & 44,8 & 50,8 & 37,3 & 4,5 & 1,5 & 3,0 & 3,0 \\
\hline 9,0 & 40,3 & 49,3 & 37,3 & 6,0 & 1,5 & -- & 6,0 \\
\hline 10,4 & 38,8 & 49,2 & 40,3 & 1,5 & 1,5 & 1,5 & 6,0 \\
\hline 13,4 & 34,3 & 47,7 & 22,4 & 6,0 & 1,5 & -- & 22,4 \\
\hline 14,9 & 31,3 & 46,2 & 31,3 & 1,5 & 6,0 & -- & 14,9 \\
\hline 14,9 & 29,9 & 44,8 & 26,9 & 3,0 & 4,5 & 1,5 & 19,4 \\
\hline 13,4 & 29,9 & 43,3 & 26,9 & 4,5 & 4,5 & 1,5 & 19,4 \\
\hline 13,4 & 29,9 & 43,3 & 31,3 & 6,0 & 4,5 & -- & 14,9 \\
\hline 4,5 & 38,8 & 43,3 & 29,9 & 1,5 & 1,5 & -- & 23,9 \\
\hline 13,4 & 28,4 & 41,8 & 41,8 & 3,0 & 1,5 & -- & 11,9 \\
\hline 9,0 & 31,3 & 40,3 & 40,3 & 3,0 & 4,5 & 3,0 & 9,0 \\
\hline 7,5 & 32,8 & 40,3 & 32,8 & 4,5 & 4,5 & -- & 17,9 \\
\hline 10,4 & 28,4 & 38,8 & 34,3 & 4,5 & 3,0 & 1,5 & 17,9 \\
\hline 4,5 & 34,3 & 38,8 & 23,9 & 3,0 & 4,5 & 3,0 & 26,9 \\
\hline 9,0 & 28,4 & 37,4 & 55,2 & 4,5 & 1,5 & -- & 1,5 \\
\hline 6,0 & 29,9 & 35,9 & 34,3 & 13,4 & 1,5 & 1,5 & 13,4 \\
\hline 6,0 & 29,9 & 35,9 & 38,8 & 3,0 & 3,0 & -- & 19,4 \\
\hline 3,0 & 31,3 & 34,3 & 35,8 & 10,4 & 1,5 & 1,5 & 16,4 \\
\hline 7,5 & 25,4 & 32,9 & 43,3 & 4,5 & -- & 1,5 & 17,9 \\
\hline 7,5 & 25,4 & 32,9 & 28,4 & 9,0 & 3,0 & 1,5 & 25,4 \\
\hline 6,0 & 26,9 & 32,9 & 44,8 & 4,5 & -- & -- & 17,9 \\
\hline 4,5 & 23,9 & 28,4 & 38,8 & 10,4 & 1,5 & 1,5 & 19,4 \\
\hline 1,5 & 17,9 & 19,4 & 31,3 & 9,0 & 4,5 & -- & 35,8 \\
\hline
\end{tabular}

Fonte: Elaborado pelo autor.

Com relação ao grau de relevância das fontes de informação mais acessadas pelos entrevistados, foi solicitado a cada um que optasse por um dos 5 (cinco) pontos da escala de relevância, sendo: 1) Totalmente irrelevante; 2) Irrelevante; 3) De alguma relevância; 4) Relevante; 5) Extremamente relevante.

Os resultados apontaram que, dentre as 10 fontes consideradas as mais relevantes pelos entrevistados (soma das opções 'Extremamente relevante' e 'Relevante'), seis são fontes pessoais, duas fontes impessoais / documentais, e duas fontes estritamente eletrônicas. Entretanto, cinco dentre as seis fontes consideradas mais relevantes são pessoais, tendo sido citadas as três fontes internas pessoais apresentadas na pesquisa, e mais duas fontes pessoais externas. A de maior relevância, para os entrevistados, é a fonte 'Diretores / Gerentes (nível tático)'. A fonte citada como a de maior frequência de busca de informações - 'Sites de busca na WEB' - é considerada a $5^{\text {a }}$ mais relevante.

Portanto, quando se considera a relevância das fontes de informação no processo de busca (Information Searching Behavior), verifica-se que as fontes pessoais se destacam entre as mais relevantes, confirmando as 
percepções de vários estudos anteriores (CHOO, 1998; BARBOSA, 2002; MAFRA PEREIRA, 2006; MAFRA PEREIRA; BARBOSA, 2008 e 2009, dentre outros) sobre a preferência por fontes pessoais quando da busca de informações mais importantes / relevantes para a solução dos problemas informacionais dos usuários.

Tabela 5 - Grau de confiabilidade com relação à fonte de informação

\begin{tabular}{|c|c|c|c|c|c|c|c|c|}
\hline Fontes de Informação & 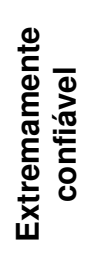 & 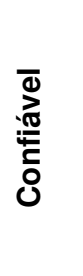 & 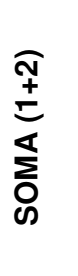 & 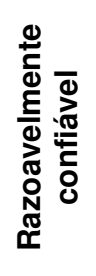 & 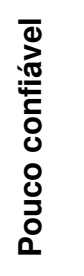 & 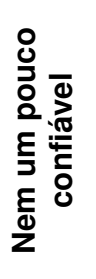 & 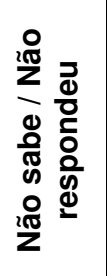 & 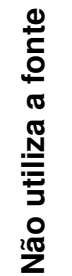 \\
\hline Diretores / Gerentes (nível tático) & $\overline{477,8}$ & 38,8 & 86,6 & 7,5 & 1,5 & $-\overline{--}$ & -- & 4,5 \\
\hline Empresários / Executivos (nível estratégico) & 37,3 & 41,8 & 79,1 & 6,0 & 4,5 & -- & -- & 10,4 \\
\hline $\begin{array}{l}\text { Leis e regulamentações / Patentes / Normas } \\
\text { Técnicas }\end{array}$ & 31,3 & 40,3 & 71,6 & 9,0 & -- & -- & -- & 19,4 \\
\hline $\begin{array}{l}\text { Relatórios, projetos e pesquisas dos setores da } \\
\text { empresa }\end{array}$ & 31,3 & 38,8 & 70,1 & 13,4 & 4,5 & 1,5 & -- & 10,4 \\
\hline Bases de dados da empresa & 37,3 & 31,3 & 68,6 & 13,4 & 6,0 & -- & -- & 11,9 \\
\hline $\begin{array}{l}\text { Memorandos / circulares / minutas / políticas e } \\
\text { normas }\end{array}$ & 25,4 & 40,3 & 65,7 & 16,4 & 6,0 & -- & 3,0 & 9,0 \\
\hline Clientes & 11,9 & 52,2 & 64,1 & 25,4 & 4,5 & -- & -- & 6,0 \\
\hline Atas de reuniões & 26,9 & 34,3 & 61,2 & 11,9 & 1,5 & -- & 3,0 & 22,4 \\
\hline Intranet / Portal Corporativo & 22,4 & 37,3 & 59,7 & 20,9 & 4,5 & -- & -- & 14,9 \\
\hline $\begin{array}{l}\text { Consultores / Analistas / Profissionais Liberais/ } \\
\text { Advogados / Publicitários / Universidades }\end{array}$ & 16,4 & 41,8 & 58,2 & 29,9 & 6,0 & -- & -- & 6,0 \\
\hline Demais empregados (nível operacional) & 4,5 & 53,7 & 58,2 & 34,3 & 4,5 & -- & -- & 3,0 \\
\hline $\begin{array}{l}\text { Biblioteca / Centro de Documentação e Informação } \\
\text { interno }\end{array}$ & 17,9 & 37,3 & 55,2 & 19,4 & 4,5 & -- & 4,5 & 16,4 \\
\hline $\begin{array}{l}\text { Sites / Portais de empresas, Universidades, } \\
\text { Governo }\end{array}$ & 10,4 & 44,8 & 55,2 & 31,3 & 9,0 & -- & 1,5 & 3,0 \\
\hline Newsletter da empresa & 20,9 & 32,8 & 53,7 & 20,9 & 7,5 & -- & -- & 17,9 \\
\hline $\begin{array}{l}\text { Periódicos de negócios / artigos / teses / } \\
\text { monografias }\end{array}$ & 14,9 & 37,3 & 52,2 & 26,9 & 1,5 & -- & -- & 19,4 \\
\hline Parceiros / Fornecedores / Distribuidores & 4,5 & 46,3 & 50,8 & 38,8 & 7,5 & -- & -- & 3,0 \\
\hline $\begin{array}{l}\text { Relatórios de negócios / financeiros / de mercado } \\
\text { (pesquisa) }\end{array}$ & 16,4 & 34,3 & 50,7 & 26,9 & -- & 1,5 & 1,5 & 19,4 \\
\hline Amigos / conhecidos / familiares & 6,0 & 41,8 & 47,8 & 43,3 & 7,5 & -- & -- & 1,5 \\
\hline Publicações governamentais & 16,4 & 31,3 & 47,7 & 20,9 & 1,5 & 1,5 & -- & 28,4 \\
\hline Congressos, feiras, eventos (anais) & 7,5 & 35,8 & 43,3 & 34,3 & 4,5 & -- & 3,0 & 14,9 \\
\hline Bancos / Agentes financeiros / Bolsa de Valores & 13,4 & 28,4 & 41,8 & 23,9 & 11,9 & -- & 3,0 & 19,4 \\
\hline Jornais e Revistas & 7,5 & 34,3 & 41,8 & 49,3 & 6,0 & -- & -- & 3,0 \\
\hline Associações comerciais / empresariais / de classe & 6,0 & 34,3 & 40,3 & 26,9 & 14,9 & -- & -- & 17,9 \\
\hline Clippings / Press releases & 7,5 & 29,9 & 37,4 & 37,3 & 3,0 & -- & 4,5 & 17,9 \\
\hline Bibliotecas públicas / de empresas & 10,4 & 26,9 & 37,3 & 20,9 & 3,0 & -- & 3,0 & 35,8 \\
\hline Rádio e TV & 3,0 & 32,8 & 35,8 & 44,8 & 11,9 & 1,5 & -- & 6,0 \\
\hline Empresários / Executivos de outras empresas & 7,5 & 23,9 & 31,4 & 38,8 & 11,9 & -- & 1,5 & 16,4 \\
\hline Sites de busca na WEB (Google, Yahoo, Wikipédia) & 4,5 & 26,9 & 31,4 & 53,7 & 14,9 & -- & -- & -- \\
\hline Funcionários de órgãos públicos / Governo & 4,5 & 25,4 & 29,9 & 37,3 & 11,9 & -- & 3,0 & 17,9 \\
\hline Material promocional de empresas / concorrentes & 6,0 & 22,4 & 28,4 & 46,3 & 11,9 & 1,5 & -- & 11,9 \\
\hline $\begin{array}{l}\text { Ex-Funcionários de empresas diversas / } \\
\text { concorrentes }\end{array}$ & 1,5 & 19,4 & 20,9 & 41,8 & 19,4 & 1,5 & 3,0 & 13,4 \\
\hline Concorrentes & 4,5 & 13,4 & 17,9 & 49,3 & 23,9 & -- & -- & 9,0 \\
\hline Newsletters de emp & 1,5 & 14,9 & 16,4 & 43,3 & 10,4 & 3,0 & 3,0 & 23,9 \\
\hline Newswires (publicações abertas online) & 1,5 & 13,4 & 14,9 & 41,8 & 11,9 & 3,0 & 3,0 & 25,4 \\
\hline
\end{tabular}

Fonte: Elaborado pelo autor.

Com relação ao grau de confiabilidade das fontes de informação mais acessadas pelos entrevistados, foi solicitado a cada um que optasse por um dos 5 (cinco) pontos da escala de confiabilidade, sendo: 1) Nem 
um pouco confiável; 2) Pouco confiável; 3) Razoavelmente confiável; 4) Confiável; 5) Extremamente confiável.

Os resultados apontaram um equilíbrio dentre as 10 fontes consideradas as mais confiáveis pelos entrevistados (soma das opções 'Extremamente confiável' e 'Confiável'): quatro delas são fontes pessoais, quatro são fontes impessoais / documentais, e duas são fontes estritamente eletrônicas. Outro aspecto interessante é que, dentre as 10 fontes mais confiáveis, sete são fontes internas às empresas nas quais os entrevistados atuam.

As fontes mais confiáveis, para os entrevistados, são 'Empresários / Executivos (nível estratégico)' e 'Diretores / Gerentes (nível tático)'. Dentre as fontes impessoais / documentais, destaque para 'Relatórios, projetos e pesquisas dos setores da empresa', 'Memorandos / circulares / minutas / políticas e normas' e 'Atas de reuniões', sendo que estas fontes não estão dentre as mais acessadas pelo público entrevistado.

Interessante também notar que a fonte citada como a de maior frequência de busca de informações - 'Sites de busca na WEB' - foi considerada apenas como a $28^{a}$ mais confiante. Como fontes estritamente eletrônicas, as mais confiáveis são fontes internas: 'Bases de dados da empresa' e 'Intranet / Portal Corporativo'.

Ainda sob o ponto de vista do comportamento de uso da informação (Information Searching Behavior), fica evidente que as fontes internas tendem a ser mais consideradas na solução das necessidades informacionais dos executivos e gestores entrevistados, face às fontes externas, devido ao critério de confiabilidade. Portanto, não há uma correlação direta entre fontes mais acessadas e fontes mais confiáveis.

\subsection{Comportamento de uso das informações pelo consultor}

Com relação ao comportamento de uso das fontes de informação pelos consultores, foi adotado o critério de Choo (2006) que afirma que as fontes de informação podem ser utilizadas para dar sentido às mudanças do ambiente externo, construir conhecimento por meio da aprendizagem ou auxiliar na tomada de decisões. Os dados apontam que a "principal finalidade" para o uso da informação coletada, pelos executivos e gestores entrevistados, é a busca de informações para embasar o processo de tomada de decisão (para 43,3\% dos entrevistados, esta é a "principal finalidade"). Como "segunda finalidade", a opção acompanhar e entender o ambiente de negócios foi citada por 46,3\%, enquanto a "terceira finalidade" mais citada pelos entrevistados $(52,2 \%)$ foi a opção gerar e construir novos conhecimentos.

\section{Considerações finais}

O comportamento de busca por informação dos executivos e gestores entrevistados apresenta diferenças quando observado sob os 
aspectos de frequência de busca, relevância e confiabilidade. Como visto anteriormente, as fontes mais acessadas, em termos de frequência, não necessariamente são as mais relevantes e, principalmente, as mais confiáveis. Estes dados merecem atenção em estudos qualitativos e exploratórios, visto que as fontes de informação eletrônicas aparecem nos primeiros lugares com relação à frequência de busca, mas com relação ao grau de confiabilidade, as mais confiáveis são as fontes pessoais internas às organizações nas quais os entrevistados atuam.

Com relação ao comportamento de uso das informações, os entrevistados as utilizam mais como subsídio para tomadas de decisões em suas atividades. A busca mais intensa por fontes eletrônicas e a maior relevância e confiabilidade nas fontes pessoais demonstra que os executivos e gestores necessitam, para tomarem decisões, de informações rápidas, de fácil acesso, mas que sejam ao mesmo tempo relevantes e confiáveis. As fontes pessoais possibilitam a este público maior rapidez na tomada de decisão por não necessitarem de um trabalho extensivo de processamento das informações, já que muitas vezes estas se caracterizam como opiniões sobre decisões pré-formatadas e já pensadas pelos entrevistados, e que são apenas comentadas, aprimoradas e/ou validadas pelos níveis tático e estratégico da empresa, e clientes e consultores externos.

Este trabalho apresenta duas limitações. A primeira refere-se ao número total de empresários e gestores entrevistados, que poderia ter sido maior, proporcionando uma análise mais estratificada por porte de empresa e a identificação de possíveis diferenças nas opiniões sobre as fontes de informação, dependendo do tamanho das organizações participantes. A segunda limitação refere-se ao fato das entrevistas terem sido realizadas apenas com empresários e gestores de empresas localizadas no Estado de Minas Gerais, cujas características regionais podem ter exercido alguma influência nas opiniões dos entrevistados sobre as fontes de informação, caso fossem comparadas com as opiniões de empresários e gestores de empresas localizadas em outros Estados brasileiros.

Os resultados são relevantes para a área da Ciência da Informação pelos motivos expostos a seguir: a definição dos tipos de fontes utilizadas por executivos e gestores pode servir de base para estudos mais aprofundados junto a este mesmo segmento, ou em outras atividades; a categorização das fontes de informação pode servir de base para outros estudos sobre fontes, bem como o comportamento de busca e de uso das informações por parte do usuário da informação; aspectos como frequência de busca, relevância e confiabilidade nas fontes são fundamentais para quaisquer outros estudos sobre fontes de informação, em qualquer atividade; e a utilização do conceito das "arenas estratégicas" (CHOO, 2006) pode servir de importante referencial para se entender, na prática, o que justifica a busca por uma ou outra informação e a consequente utilização de determinadas fontes em detrimento de outras. Finalmente, outra linha de estudos futuros poderia explorar a 
frequência de uso, relevância e confiabilidade das fontes exclusivamente eletrônicas, bem como o avanço das redes sociais neste contexto.

\section{Referências}

AGUILAR, F. J. Scanning the business environment. New York, NY: Macmillan, 1967.

AUSTER, E.; CHOO, C. W. How senior managers acquire and use information in environmental scanning. Information Processing and Management, v. 30, n. 5, p. 607-618, 1994.

BARBOSA, R. R. Inteligência empresarial: uma avaliação de fontes de informação sobre o ambiente organizacional externo. DataGramaZero Revista de Ciência da Informação, Belo Horizonte, v. 3, n. 6, dez. 2002.

CARMO, V. B.; PONTES, C. C. C. Sistemas de informação gerenciais para programa de qualidade total em pequenas empresas da região de Campinas. Ciência da Informação, Brasília, v. 28, n. 1, p. 49-58, jan./abr. 1999.

CENDÓN, B. V. Bases de dados para negócios. Ciência da Informação, Brasília, v. 31, n. 2, p. 30-43, maio/ago. 2002.

CENDÓN, Beatriz Valadares. Bases de dados para negócios no Brasil. Ciência da Informação, Brasília, v. 32, n. 2, p. 17-36, maio/ago. 2003.

$\mathrm{CHOO}, \mathrm{C}$. W. Perception and use of information sources in environmental scanning. Library \& Information Science Research, v. 16, n. 1, p. 23-40, 1994.

$\mathrm{CHOO}$, Chun Wei. Information management for the intelligent organization: the art of scanning the environment. 2. ed. Medford, New Jersey: ASIS Monograph Series, 1998.

$\mathrm{CHOO}, \mathrm{C}$. W. The knowing organization: how organizations use information to construct meaning, create knowledge, and make decisions. 2. ed. New York: Oxford University Press, 2006.

DEGENT, R. J. A importância estratégica e o funcionamento do serviço de inteligência empresarial. Revista de Administração de Empresas, v. 26, n. 1, p. 77-83. Jan./mar. 1986.

FIGUEIREDO, N. Informação para negócios: um novo desafio. In: CONGRESSO LATINO-AMERICANO DE BIBLIOTECONOMIA E DOCUMENTACAO, 2., 1994, Belo Horizonte. Anais... Belo Horizonte: ABMG, 820 p., 1994.

FULD, L. M. Dez maneiras fáceis de monitorar seus concorrentes. In: FULD, L.M. Administrando a concorrência. Rio de Janeiro: Record, 1993.

KOBRIN, S. J. et al. The assessment and evaluation of noneconomic environments by American firms. Journal of International Business Studies, n. 11, p. 32-47, 1980. 
LESCA, H.; ALMEIDA, F. C. Administração estratégica da informação. Revista de Administração, São Paulo, v. 29, n. 3, p. 66-75, jul./set. 1994.

LESTER, R.; WATERS, J. Environmental scanning and business strategy. London, UK: British Library, Research and Development Department, 1989.

MAFRA PEREIRA, F. C. Fundamentos metodológicos da pesquisa de Marketing. 2000. 68 f. Monografia (Especialização lato sensu em Gestão Estratégica de Marketing) - Centro de Pós-Graduação e Pesquisas em Administração da Universidade Federal de Minas Gerais, Belo Horizonte, 2000.

MAFRA PEREIRA, F. C. Uso de fontes de informação: um estudo em micro e pequenas empresas de consultoria de Belo Horizonte. 2006. $154 \mathrm{f}$. Dissertação (Mestrado em Ciência da Informação) - Escola de Ciência da Informação, UFMG, Belo Horizonte, 2006.

MAFRA PEREIRA, F. C.; BARBOSA, R. R. Uso de fontes de informação por consultores empresariais: um estudo junto ao mercado de consultoria de Belo Horizonte. Perspectivas em Ciência da Informação, Belo Horizonte, v. 13, n.1, p. 95-111, 2008.

MAFRA PEREIRA, F. C., BARBOSA, R. R. A decisão estratégica por executivos de micro e pequenas empresas e a cadeia alimentar informacional como modelo integrativo de fontes de informação. In: ENCONTRO NACIONAL DE PESQUISA EM CIÊNCIA DA INFORMAÇÃO ENANCIB, 10., João Pessoa, 2009. Anais... João Pessoa: UFPB, 2009. p.1113-1131.

MALHOTRA, N. K. Pesquisa de Marketing: uma orientação aplicada. 3. ed. Porto Alegre: Bookman, 2001.

MATTAR, F. N. Pesquisa de Marketing. São Paulo: Atlas, 1996.

MONTALLI, K. M. L. Information in the capital goods industry in Brazil. Loughborough: Loughborough University of Technology, 1987.

MONTALLI, K. M. L. Informação para negócios no Brasil: reflexões. In: SEMINARIO NACIONAL DE INFORMACAO PARA INDÚSTRIA E COMERCIO EXTERIOR, 1., 1993, Belo Horizonte. Anais... Belo Horizonte: UFMG/EB, 1994., p. $165-173$.

PEREIRA, M. F. F. Gerenciamento da informação: um diagnóstico da micro e pequena empresa industrial de Londrina. 2003. 154 f. Dissertação (Mestrado em Engenharia de Produção) - Universidade Federal de Santa Catarina, Florianópolis, 2003.

POZZEBON, M.; FREITAS, H. M. R. de; PETRINI, M. Pela Integração da inteligência competitiva nos Enterprise Information Systems (EIS). Ciência da Informação, Brasília, n. 3, v. 26, p. 243-254, set./dez.1997.

SAMARA, B. S., BARROS, J. C. de. Pesquisa de Marketing: conceitos e metodologia. 3. Ed. São Paulo: Prentice Hall, 2002. 
SERVIÇO DE APOIO ÀS MICRO E PEQUENAS EMPRESAS (SEBRAE). Disponível em: <http://www.sebrae.com.br/sites/PortalSebrae/>. Acesso em: 25 jul. 2015.

SMELTZER, L. R.; FANN, G. L.; NIKOLAISEN, V. N. Environmental scanning practices in small businesses. Journal of Small Business Management, v. 26, n. 3, p. 55-62, 1988.

SOUZA, T. de F. C. de; BORGES, M. E. N. Instituições provedoras de informação tecnológica no Brasil: análise do potencial para atuação com informação para negócios. Ciência da Informação, Brasília, v. 25, n. 1, p. 52-58, jan./abr. 1996.

SUTTON, H. Competitive intelligence. New York: The Conference Board, 1988. (Conference Board Research Report, n. 913).

WILSON, T. D. Human information behavior. Information Science Research, v. 3, n. 2, p.49-55, 2000. 